\title{
Avaliação do Conhecimento e o Uso de Isotretinoína com Alunos de uma Instituição de Ensino Superior do Município de Anápolis-Goiás
}

\section{Evaluation of the Knowledge and Use of Isotretinoin with Study from a Higher Education Institution of the Municipality of Anapolis-Goias}

\author{
Erick de Oliveira Lemes ${ }^{a}$; Aleixo Francisco de Andrade $e^{a}$ Erika Amaral Diniz $z^{\text {a }}$ Geysse de Cubas Vieira Soares*a
}

a Universidade Anhanguera. GO, Brasil.

*E-mail: ge.soares43@outlook.com

\begin{abstract}
Resumo
A isotretinoína pertence a um grupo de medicamentos chamados resinoides, relacionados à vitamina $\mathrm{A}$, é conhecida por Roacutan ${ }^{\circledR}$, sendo indicada em diversas dermatoses, principalmente na acne nodulocística. A sua ação baseia-se na diminuição do tamanho das glândulas sebáceas, diminuindo a produção de sebo, possibilitando a inibição da formação de comedões que ocorre pela ação do Propionibacterium acnes, responsável pelo processo inflamatório cutâneo e pela estimulação da produção de anticorpos. Este trabalho teve como objetivo avaliar o conhecimento e o uso de isotretinoína com alunos de uma instituição de ensino superior do município de Anápolis-Goiás. Foi desenvolvido uma pesquisa, com alunos de uma instituição de ensino superior do município de Anápolis, Goiás, através de questionário, semiestruturado. Observou-se que $66.67 \%$ dos alunos alcançaram o resultado pretendido e $33.33 \%$ não obtiveram êxito quanto ao tratamento, mostrando-se insatisfeitos com a Isotretinoína. Vale ressaltar também que todos os pacientes afirmaram estar cientes dos efeitos nocivos da isotretinoína durante o tratamento. Com a realização deste estudo é possível concluir que ambos os sexos procuram o uso da isotretinoína para tratamento. Desta forma, o estudo realizado buscou conhecer mais sobre o perfil dos usuários desse fármaco, juntamente com os efeitos adversos mais apresentados e se houve recidivas da acne após o uso.
\end{abstract}

Palavras-chave: Retinóides. Roacutan. Pacientes.

\begin{abstract}
Isotretinoin belongs to a group of medicamen called resinoids, related to vitamin A, is known as Roacutan ${ }^{\circledR}$, being indicated in several dermatoses, mainly in doducteistic acne. Its action is based on the decrease in the size of sebaceous glindils, decreasing the production of sebum, allowing the inhibition of the formation of comesn that occurs by the action of Propionibacterium acnes, responsible for the cutaneo inflamasorous process and the desatimization of antibody production. This study aimed to evaluate the knowledge and use of isotretinoin with alums from a higher education institution of the municipality of Anápolis-Goiás. A research was conducted with alums from a higher education institution in the municipality of Anápolis, Goiás, through a semi-structured questionnaire. It was observed that $66.67 \%$ of the students achieved the intended result and $33.33 \%$ were unsuccessful in treatment, showing to be dissatisfied with Isotretinoin. It is also worth mentioning that all pacients stated that they were aware of the harmful effects of isotretinoin during treatment. With the implementation of this esudo it is possible to agree that both sexes seek the use of isotretinoin for treatment. Thus, the edudo realiso sought to know more about the profile of users of this drug, along with the most presented adverse effects and whether there was a relapse of acne after use.
\end{abstract}

Keywords: Retinoids. Roacutan. Patients.

\section{Introdução}

A Isotretinoína é um derivado da vitamina A pertencente a um grupo de medicamentos chamados retinóides, sendo quimicamente denominada de ácido-13-cisretinóico, suas características farmacocinéticas são análogas às da vitamina A. Encontra-se na lista C2 de Substâncias Retinóicas da Portaria 344/1998, a qual sua prescrição necessita estar em Receituário de Controle Especial em duas vias e a receita deverá ser retida no ato da compra (SAMPAIO; BAGATIN, 2008).

Sua ação baseia-se na redução do tamanho das glândulas sebáceas, diminuindo a produção de sebo, inibição da formação de comedões, combatendo o microrganismo Propionibacterium acnes, responsável pelo processo inflamatório cutâneo e pela estimulação da produção de anticorpos. Suas concentrações plasmáticas são atingidas durante duas a quatro horas após ocorrer administração oral (KNUTSON; PERSHING, 2004).

Os efeitos adversos apresentados durante a utilização da Isotretinoína foram divididos em dois grupos: mucocutâneos e sistêmicos, sendo o principal e mais arriscados durante o tratamento, a teratogenicidade. Torna imprescindível a conscientização do paciente dos riscos de sua utilização, tais como alterações em órgãos ou sistemas tal como o fígado, olhos, sistema nervoso central, sistema hematopoiético e sistema endócrino(VALADARES; RIBEIRO; BERNARDES, 2012).

A isotretinoína é comercializada com o nome de Roacutan ${ }^{\circledR}$, sendo indicada para o tratamento de dermatoses, principalmente na acne nodulocística, na pitiríase rubro pilar, dermatite seborreica, psoríase postular, quimioprevenção do câncer, foliculites e quadros de acne resistentes a terapêuticas 
anteriores como antibióticos sistêmicos e agentes tópicos (MADEIRA, 2012).

Os efeitos colaterais da isotretinoína incluem: secura labial e bucal, dores musculares, crises de asma, queda de cabelo e alterações do colesterol, tem efeito fotossensibilizante, sendo recomendável evitar a exposição solar ao usar a medicação. Os efeitos colaterais podem influenciar o SNC e causar depressão e seus efeitos (DUAILIBE; ALVES, 2007).

A utilização desse fármaco não é indicada para mulheres que planejam engravidar em um período curto, pois ele afeta o desenvolvimento do sistema nervoso central do feto causando má formação fetal. Também não deve ser utilizado por pessoas com problemas de insuficiência hepática, hipervitaminose A, hiperlipidemias e que fazem o uso de bebidas alcoólicas. No Brasil o uso da isotretinoína é restrito pelo alto custo da medicação, pelo seu rigoroso termo a ser assinado pelo paciente, à demora no trâmite burocrático pelo SUS para liberações da medicação (BRASIL, 2010; DINIZ, 2002).

A isotretinoína é um tratamento farmacológico de sucesso para acne, pois é um fármaco de alta eficácia, buscada por muitos pacientes que vão a consultórios dermatológicos com intuito de melhores resultados (VALADARES; RIBEIRO; BERNARDES, 2012).

A acne acomete grande parte da população de ambos os sexos, elas surgem principalmente na puberdade e permanece ate a fase adulta. A acne é uma patologia de caráter inflamatório da unidade pilo sebácea, patologia caracterizase pela presença dos denominados comedões, pápulas em forma de eritema, pústulas, e em certos casos, aparecimento de nódulos e pseudocistos (SCHMIDT; SILVA, 2009).

Esse trabalho objetivou realizar um estudo sobre o perfil socioeconômico e terapêutico dos usuários da isotretinoína, buscando conhecer mais sobre o perfil dos usuários desse fármaco, juntamente com os efeitos adversos mais apresentados e se houve reicidiva da acne após o uso.

\section{Desenvolvimento}

\subsection{Metodologia}

Trata-se de pesquisa descritiva, com abordagem quantitativa. Na pesquisa quantitativa, uma das maneiras da realização desta, consiste em empregar parâmetros que garantam resultados com precisão, possibilitando uma margem de segurança quanto às interferências (RICHARDSON, 1999).

A pesquisa descritiva tem como principal objetivo descrever características de determinada população ou fenômeno ou o estabelecimento de relações entre as variáveis. Uma de suas características mais significativas está na utilização de técnicas padronizadas de coletas de dados (RICHARDSON, 1999).

A pesquisa foi realizada em uma instituição de ensino superior, localizada no município de Anápolis, estado de Goiás, durante os meses de agosto, setembro e outubro de 2015. A amostra foi composta de 300 universitários matriculados nos cursos de Biomedicina, Farmácia, Nutrição e Veterinária da Faculdade Anhanguera de Anápolis.

Os dados foram coletados com o auxílio da aplicação de um questionário composto por dez questões, onde foram avaliadas as seguintes variáveis: idade, gênero, efeitos adversos e se está usando pela primeira vez ou não.

A utilização de um questionário como técnica de pesquisa faz com que informações sejam coletadas e possam ser mensuradas estatisticamente obtendo-se resultados quantitativos ${ }^{13}$.

Todos os dados foram copilados, de forma quantitativa, com o auxílio do software Microsoft Excel®. Os dados foram apresentados sob forma de gráficos e tabelas, analisados e discutidos.

A pesquisa não oferece riscos aos sujeitos participantes, visto que os dados coletados foram publicados sem que haja correlação e identificação dos participantes. Em qualquer etapa da pesquisa, o participante que desejou não participar da pesquisa teve seu direito assegurado.

Foram incluídos na pesquisa os acadêmicos que aceitaram participar da pesquisa mediante a assinatura do TCLE, maiores de 18 anos e de ambos os sexos. Foram excluídos da pesquisa: participantes que não aceitaram os termos do TCLE.

A pesquisa foi realizada mediante a submissão e aprovação do Comitê de Ética em Pesquisa, sob o número de protocolo: 098215/2015. Todos os questionários respondidos foram armazenados em poder dos pesquisadores pelo prazo de cinco anos. Os pesquisadores assumiram total responsabilidade pelo desenvolvimento de todas as etapas da pesquisa, bem como o financiamento da mesma, visto que não existiu nenhuma empresa ou instituição auxiliando financeiramente a mesma.

\subsection{Resultados e Discussão}

A pesquisa foi efetivamente realizada conforme o previsto, sendo que as entrevistas foram feitas com 300 voluntários, sendo mulheres a maioria do número amostral que utilizavam a isotretinoína, representando $60.33 \%$, homens representaram $35.67 \%$. Observou-se que $71 \%$ dos entrevistados encontravamse na faixa etária entre 18 a 25 anos, $21.33 \%$ entre 26 a 35 anos, $4.33 \%$ de 36 a 45 anos, $1.67 \%$ de 46 a 55 anos, $1 \%$ de 56 a 65 anos e $0.33 \%$ acima de 70 anos. Quanto ao estado civil a maior parte dos pesquisados foi caracterizada como solteiros, totalizando $73.33 \%$; casados com $19.67 \%$, separados $2.33 \%$, divorciados $3.33 \%$, outros representaram $1.33 \%$.

Os entrevistados cursavam os cursos de Biomedicina, totalizando 60 participantes do número total de entrevistados, Farmácia 104, Nutrição 40 e Medicina Veterinária 96, conforme a Figura 1. 
Figura 1 - Cursos de graduação e total de estudantes pertencentes a cada

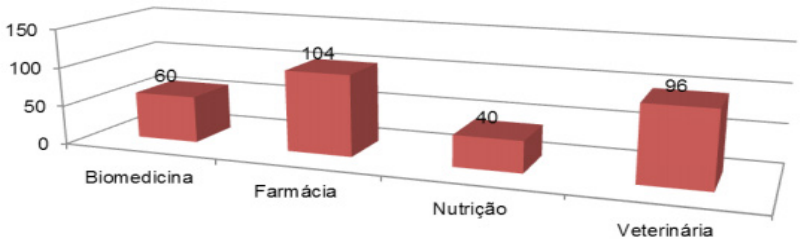

Fonte: Dados da pesquisa

A renda mensal dos participantes também variou muito, com entrevistados com renda de menos de um salário mínimo, representando 112, entre dois a cinco salários mínimos 154 , de seis a oito salários mínimos 12 , de nove a dez salários mínimos 12 e com rendas mensais acima de 10 salários mínimos, representando 10 dos entrevistados, conforme mostra a figura 2 .

Figura 2 - Renda mensal média dos entrevistados

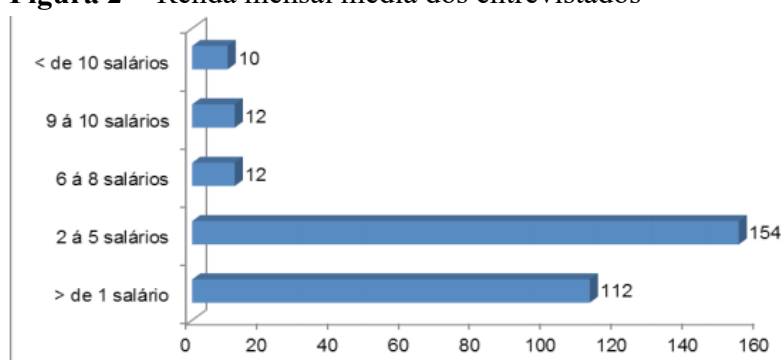

Fonte: Dados da pesquisa

Em relação a presença de reações adversas, 100\% afirmaram apresentá-las frente ao uso de isotretinoína. Sendo que $13.89 \%$ dos pacientes reclamaram de depressão, já $41.67 \%$, dor de cabeça, 25\% falta de ar, $11.11 \%$ tiveram aumento do colesterol e $41.67 \%$ reclamaram de ressecamento dos olhos. Dentre as 300 pessoas que utilizaram a isotretinoína, observou-se que $66.67 \%$ alcançaram o resultado pretendido e $33.33 \%$ não obtiveram êxito quanto ao tratamento mostrandose insatisfeitos com o medicamento. O percentual de pessoas que informaram que estavam utilizando a isotretinoína no momento de responder aos questionários foram de $12 \%$ e $88 \%$ não disseram que não estavam utilizando o medicamento naquele momento.

Após a realização da pesquisa, observou-se que a porcentagem de pessoas do sexo feminino e masculino que procuraram pelo tratamento com a isotretinoína era de $60.33 \%$ feminino e $35.67 \%$ masculino. Esses dados se assemelham a pesquisa realizada por Madeira (2012), onde pesquisou a tolerabilidade da isotretinoína oral. Segundo esse autor, dos pacientes estudados, a maioria eram do sexo feminino, mostrando efetivamente que tanto homens quanto mulheres em proporções semelhantes procuram tratamento para acne.

Em relação à idade notou-se que a maioria dos indivíduos em tratamento possuía idade de entre 18 a 25 anos, mostrando que muitas vezes a acne não acaba no fim da puberdade. As lesões começam a surgir na puberdade, atingindo a maioria dos jovens de ambos os sexos (tendo um maior pico de incidência dos 12 aos 25 anos). A acne começa a surgir principalmente na puberdade, sendo jovens de ambos sexos, mas também pode atingir a fase adulta, que vai de 26 a 35 anos (SILVA et al., 2009).

Quanto aos principais efeitos adversos relatados pelos entrevistados, $100 \%$ afirmaram apresentá-las frente ao uso de isotretinoína, apresentando mais de um efeito colateral. Sendo que $13.89 \%$ dos pacientes reclamaram de sofrer depressão, $41.67 \%$, dor de cabeça, $25 \%$ falta de ar, $11.11 \%$ tiveram aumento do colesterol e $41.67 \%$ reclamaram de ressecamento dos olhos.

A pesquisa mostra que pacientes que fizeram o uso da isotretinoina, todos realizaram exames laboratoriais, e que no final do tratamento os resultados, das 36 pessoas que usaram o medicamento, foram; 24 pessoas obtiveram efeito terapêutico e 12 pessoas não conseguiu efeito terapêutico. Em relação ao percentual de pacientes que está fazendo tratamento com isotretinoína pela primeira vez ou não, observou-se que $80 \%$ dos entrevistados relataram que o está fazendo pela primeira vez.

Para Sampaio, Batagin (2008), cerca de 2\% dos casos são mais resistentes ao tratamento; em geral, são homens ou mulheres com problemas hormonais. Nesses casos pode ser necessário prolongar o uso da isotretinoína por mais um ou três meses.

O fato de muitos estarem fazendo o tratamento pela segunda vez é devido às recidivas que, segundo os autores, parecem ser mais frequentes, sobretudo quando são utilizadas subdoses, embora outros fatores possam estar envolvidos. Com doses adequadas o risco de recidiva, com necessidade de outro ciclo de tratamento, é inferior a $1 \%$ (SAPAIO; BETAGIN, 2008).

Quanto ao tempo de tratamento $81.8 \%$ dos pacientes afirmaram que fizeram o uso de isotretinoína durante 6 meses. No estudo feito por Nascimento et al. (2011), o tempo médio de uso de isotretinoína foi de 8,6 meses, sendo o tratamento mais curto de quatro meses, e o mais longo de 15 meses (NASCIMENTO, 2011). Quanto aos principais efeitos adversos relatados pelos pacientes, $13.89 \%$ relataram sofrer de depressão, já $41.67 \%$, dor de cabeça, 25\% falta de ar, $11.11 \%$ tiveram aumento do colesterol e $41.67 \%$ reclamaram de ressecamento dos olhos, estes os principais efeitos encontrados.

Em um estudo realizado por Furtado \& Santos (1990), com usuários de isotretinoína, também se pode observar que a secura das mucosas como reação adversa era a mais frequente $(80 \%)$ ao tratamento com a isotretinoína. Segundo esse mesmo autor o ressecamento dos lábios é um efeito colateral relacionado à Hipervitaminose, assim como, secura dos olhos, da mucosa nasal e queda de cabelo (FURTADO; SANTOS, 1990).

Vale ressaltar também que todos os pacientes afirmaram estar cientes dos efeitos nocivos da isotretinoína durante o 
tratamento. Segundo Schmidt, Silva (2009), o uso restrito da isotretinoína se deve pelo número exacerbado de efeitos adversos, com grande ação teratogênica, devido a isto, o usuário deverá estar totalmente informado sobre suas reações antes do início do tratamento.

Em relação ao período em que ocorreram os primeiros sintomas pelo uso da isotretinoína, na maioria dos pacientes (59\%) foi constatado o aparecimento durante o início do tratamento e em (41\%) dos entrevistados ocorreram durante o tratamento. Com base nos artigos consultados não foram encontrados parâmetros para inferir sobre a qualificação destes valores.

A isotretinoína apresenta restrições relacionadas a alterações laboratoriais, principalmente nos efeitos no perfil lipídico. Furtado e Santos (1990) concluíram por meio de estudos, que as alterações do colesterol e das triglicérides, implicam em possíveis riscos de doenças coronarianas e que a redução à normalidade ocorreu após o término do tratamento.

Quanto ao nível de satisfação em relação ao tratamento da acne $66.67 \%$ definiram como bom e $33.33 \%$ definiram como ruim. Embora cada caso deva ser individualizado, em geral, após três meses de tratamento, já se percebe melhora e uma real satisfação dos pacientes ${ }^{15}$.

\section{Conclusão}

Com a realização deste estudo é possível concluir que ambos os sexos procuram o uso da isotretinoína para tratamento. Desta forma, o estudo realizado buscou conhecer mais sobre o perfil dos usuários desse fármaco, juntamente com os efeitos adversos mais apresentados e se houve recidivas da acne após o uso.

As reações adversas representam riscos, principalmente entre adolescentes e mulheres em idade fértil, que devem ter um acompanhamento farmacoterapêutico especial durante o tratamento. O uso de bebidas alcoólicas é proibido com o uso do medicamento podendo causar grande sobrecarga no fígado trazendo vários riscos. Em relação aos efeitos colaterais torna-se essencial o monitoramento clínico do paciente antes, durante e após o término do tratamento.

É importante que o acompanhamento seja realizado pelo profissional farmacêutico, em qualquer estabelecimento no qual a isotretinoína for dispensada, através da realização da Atenção Farmacêutica. Vê-se então que a isotretinoína é um medicamento a ser utilizado com segurança, se for acompanhado em caráter multidisciplinar por um médico e por um farmacêutico, nos casos de acne vulgar, para os quais os benefícios superam os riscos.

\section{Referências}

SAMPAIO, S.A.P.; BAGATIN, E. Experiência de 65 anos no tratamento da acne e de 26 anos com isotretinoína oral. Anais Bras. Dermatol., v.83, n. 4, p. 361-367, 2008. doi: 10.1590/ S0365-05962008000400012

BRASIL. Protocolo Clínico e Diretrizes Terapêuticas: acne grave. Portaria SAS/MS n 143 , de 31 de março de 2010.

BEZZON, L.C. Manual para elaboração de trabalhos acadêmicos. Campinas: Alínea, 2009.

DINIZ, D. Isotretinoína: perfis farmacológico, farmacocinético e analítico. Rev. Bras. Ciênc. Farm., v.38, n. 4, p. 17-26, 2002. doi: 10.1590/S1516-93322002000400004.

DUAILIBE, D.S.; ALVES. N.S. Isotretinoina amplitude terapêtica e potencialidade tóxica. Araguaína: FAHESA/ ITPAC, 2007.

FURTADO, T.; SANTOS, S.M.B. Tratamento da acne pela isotretinoína: Contra indicações e argumentos contrários. Anais Bras. Dermatol., v.65, n. 5, p. 37-42, 1990.

KNUTSON, K.; PERSHING, L.K. Medicamentos Tópicos. In: GENNARO, A.R.R. A ciência e a prática da farmácia. Rio de Janeiro: Guanabara Koogan, 2004.

MADEIRA, N. Isotretinoína, depressão e suicídio. Rev. Psiquiatr. Clín., v.2, n.39, p.76-77, 2012.

NASCIMENTO, C.R. Recidiva de acne após tratamento com isotretinoína oral: seguimento de cinco anos. Surg. Cosm. Dermatol., v.3, n. 3, p. 188-191, 2011.

SAMPAIO, S.A.P. Dermatologia. São Paulo: Artes Médicas, 2007.

SCHMIDT, G.M.; SILVA, C.B. Isotretinoína: utilização no tratamento da acne e aspectos fundamentais para a atenção farmacêutica. Infarma, v.21, n. 5, 2009.

SILVA, J.E.D.S. et al. Isotretinoína no tratamento da acne: riscos e benefícios. Rev. Bras Farm., v.90, n.3, p.1-23, 2009.

RICHARDSON, R.J. Pesquisa social: métodos e técnicas. São Paulo: Atlas, 1999.

VALADARES, J.V.; RIBEIRO, L.O.C.; BERNARDES, T.D. Efeitos teratogênicos da isotretinoina. Araguaína, FAHESA/ ITPAC, 2012. 